\title{
The molecular mechanism of \\ enantiorecognition of tertiary alcohols by carboxylesterases
}

Erik Henke ${ }^{[a]}$, Uwe T. Bornscheuer ${ }^{[b]}$, Rolf D. Schmid ${ }^{[a]}$, Jürgen Pleiss ${ }^{[a]} *$

[a] Dr. Erik Henke, Prof. Dr. Rolf D. Schmid, PD Dr. Jürgen Pleiss

Institute of Technical Biochemistry

University of stuttgart,

Allmandring 31

D-70569 Stuttgart, Germany

[b] Prof. Dr. Uwe T. Bornscheuer

Institute of Chemistry and Biochemistry

Greifswald University

Soldmannstr. 16

D-17487 Greifswald, Germany

* Corresponding author:

Tel.: +49711-685-3191

Fax: +49711-685-3196

email: itbjplepo.uni-stuttgart.de 


\section{Abstract}

Carboxylesterases containing the sequence motif GGGX catalyze hydrolysis of esters of chiral tertiary alcohols, albeit at only low to moderate enantioselectivity towards three model substrates (linalyl acetate, methyl-1-pentin-1-yl acetate, 2-phenyl3-butin-2-yl acetate). In order to understand the molecular mechanism of enantiorecognition and to improve enantioselectivity towards this interesting substrate class, the interaction of both enantiomers with the substrate binding sites of acetylcholinesterases and $p$ nitrobenzyl esterase from Bacillus subtilis was modeled and correlated to experimental enantioselectivity. For all substrate-enzyme pairs, enantiopreference and ranking by enantioselectivity could be predicted by the model. In p-nitrobenzyl esterase, one of the key residues in determining enantioselectivity was G105: exchange of this residue by alanine led to a six-fold increase of enantioselectivity (E=19) towards 2-phenyl-3-butin-2-yl acetate. However, the effect of this mutation is personalized: towards the substrate linalyl acetate, the same mutant had a reversed enantiopreference. Thus, depending on the substrate structure, the same mutant had either increased enantioselectivity or opposite enantiopreference compared to wild type enzyme. 
Keywords: enantioselectivity, enzyme catalysis, molecular modeling, protein design, tertiary alcohols

Abbreviations: PLE, pig liver esterase; AChEs, acetylcholine esterases from electric eel (eeAChE), human (hAChE), and Bungarus fasciatus (bAChE); CRL, Candida rugosa lipase; BsubpNBE, Bacillus subtilis p-nitrobenzyl esterase; pNPA, para-nitrophenyl acetate; WT, wild type; TA, tertiary alcohol; TAE, ester of tertiary alcohol. 


\section{Introduction}

One of the key questions in understanding structurefunction relationship of enzymes is how they distinguish between the two enantiomers of a chiral substrate. Lipases (E.C. 3.1.1.3) and esterases (E.C. 3.1.1.1) are widely used as enantioselective catalysts by organic chemists. [1, 2] Although lipases and esterases show no general sequence similarity, they share a common architecture, the $\alpha / \beta$ hydrolase fold, ${ }^{[3]}$ which consists of 8 central $\beta$ strands surrounded by $\alpha$ helices. Also their catalytic mechanism is identical: the catalytic machinery consists of an amino acid triad (serine, histidine and aspartate or glutamate) with the serine acting as a nucleophile, attacking the carbonyl carbon of the substrate ester, while the histidine acts as an amphiphile catalyzing the withdrawal of the alcohol moiety by transferring a proton on the ester oxygen. [4]

Most lipases and esterases show enantiorecognition towards chiral alcohols or carboxylic acids, but enantioselectivity often is not high enough for industrial applications. In order to use them in chiral synthesis, their enantioselectivity can be further increased by substrate engineering, ${ }^{[5]}$ solvent variation, [6] immobilization, [7] the modification of 
parameters like temperature, ${ }^{[8]} \mathrm{pH},{ }^{[9]}$ and pressure, [10] or by modification of the enzyme's structure. Several attempts to vary enantioselectivity of esterases and lipases by directed evolution, [11-13] and by rational protein engineering were successful. ${ }^{[14}$, 15] The latter method also yields insight into the molecular mechanism of enantiorecognition. X-ray structures of several lipases and esterases complexed with chiral substrate analogous inhibitors are available. This made it possible to understand the structural basis of an empirical rule for predicting the enantiopreference towards esters of secondary alcohols from the structure of the substrate only. [16, 17] However, for other substrates like small primary alcohols and triacylglycerols such an universal rule for all lipases is not applicable.[18] In general, enantiopreference depends on the details of the structure of both, the substrate and the enzyme. Methods of computer-aided molecular modeling have been successfully used to study those interactions and identify determinants of enantioselectivity. ${ }^{[19-21]}$

The synthesis of optically pure substances with a quaternary stereogenic center is still a challenge, not only in biocatalysis but also in classical stereoselective synthesis. ${ }^{[22]}$ A promising route to an optically pure compound with a quaternary stereogenic center is via esterase-catalyzed kinetic resolution of 
chiral tertiary alcohols. While carboxylester hydrolases are widely used for the synthesis of optically pure secondary alcohols and to a smaller extend also for the resolution of primary alcohols and carboxylic acids, [1, 23] there are only few examples of an utilization for the hydrolysis of esters of tertiary alcohols (TAEs). Tertiary alcohols (TAs) are generally not accepted as substrates by almost all carboxylester hydrolases of commercial interest probably due to the sterically demanding structure of those compounds. ${ }^{[24,}{ }^{25]}$ The only hydrolases which are active towards this class of substrates are characterized by a highly conserved GGG(A)X-motif, ${ }^{[26]}$ which is located in the active site and contributes to the formation of the so-called oxyanion hole. ${ }^{[27]}$ This binding pocket stabilizes the oxyanion in the tetrahedral intermediate formed during the catalytic cycle of ester hydrolysis. ${ }^{[28]}$. GGG(A)X-type hydrolases are mostly carboxylesterases and often from eukaryotic origin. In contrast, most bacterial lipases and esterases, which are preferentially used in biotransformation do not show this GGG(A)X-motif but a GX-pattern. Both groups, GGG(A)X- and GX-hydrolases, differ significantly in the structure of the catalytic site. ${ }^{[27]}$ Recently, our findings that GGG(A)X-type hydrolases are able to hydrolyze esters of tertiary alcohols were confirmed by the discovery of an tert.- 
butyl acetate hydrolyzing GGG(A)X-type esterase from the hyperthermophilic archaeon Pyrobaculum calidifontis. [29]

To understand the molecular mechanism of enantiorecognition of tertiary alcohols by carboxylesterases, enantioselectivity of several enzymes towards esters of chiral tertiary alcohols were investigated in vitro and in silico. With a refined computer-based model it was possible to explain the experimentally observed enantioselectivity and to predict the effect of mutations. 


\section{Results}

\section{Enantioselectivity}

Seven GGG(A)X-type carboxylesterases were tested for their enantioselectivity towards chiral TAEs: two preparations of pig liver esterase (PLE), acetylcholine esterases from banded krait (Bungarus fasciatus, bAChE), electric eel (Electrophorus electricus, eeAChE), and human (hAChE), lipase from Candida rugosa (CRL) and a recombinant $p$-nitrobenzyl esterase from Bacillus subtilis (BsubpNBE) . Hydrolytic reactions were performed using a pH-stat. Enzyme-catalyzed hydrolysis of three model substrates (Figure 1) occurred with only low to moderate enantioselectivity (Table 1 ). Linalyl acetate $\mathbf{1}$ was converted by all hydrolases uniformly with enantioselectivities of $E<2$, CRL did not show any enantiorecognition at all. Interestingly, the two commercial PLE preparations (Chirazyme E1 and E2, Roche, Mannheim) displayed opposite enantiopreference, albeit at a very low level of enantioselectivity. For 3-methyl-1pentin-3-yl acetate $\mathbf{2}$, the hydrolases differed in the degree of enantiorecognition: enantioselectivities between $E=3$ and $E=7$ were obtained with PLE and the AChEs. Towards this substrate, CRL showed lower enantioselectivity $(E=2)$, while BsubpNBE was nonselective $(E=1)$. Considerable differences in enantioselectivity were obtained using 2-phenyl-3-butin- 
2-yl acetate $\mathbf{3}$ as substrate: the AChEs converted $\mathbf{3}$ with the highest enantioselectivity $(E=3-10)$, while PLE E1 $(E=1.3)$ had very low and $\operatorname{CRL}(E=1)$ no enantioselectivity. PLE E2 was significantly more selective $(E=5)$ than the El preparation. BsubpNBE $(E=$ 3) accepted 3 with higher enantioselectivity than substrates $\mathbf{1}$ and $\mathbf{2}$.

The various AChEs showed considerably different enantioselectivity towards the substrate $\mathbf{2}$ and particularly substrate 3. While eeAChE and hAChE converted both substrates with $E=4$ and $E=3$, respectively, bAChE was more selective $(E=7$ and $E=10$ towards $\mathbf{2}$ and $\mathbf{3}$, respectively).

\section{Modeling of AChEs}

The difference in the enantioselectivity of eeAChE and bAChE was modeled by comparing the interactions between the two substrate enantiomers and the binding site of the esterases. While the structure of eeAchE (PDB entry $1 \mathrm{C} 2 \mathrm{~B})^{[30]}$ and hAChE (PDB entry 2CLJ, homology model) ${ }^{[31]}$ are available, the structure of bAChE has not yet been determined. bAChE has a sequence identity of $55 \%, 57 \%$, and $65 \%$ to eeAChE, hAChE, and to AChE from Torpedo californica (tcAChE), respectively. Consequently, the structure of bAChE was modeled based on the tcAChE structure (PDB entries $1 Q I K$ and $1 \mathrm{CFJ}) .{ }^{[32]}$ While the 
overall sequence similarity of eeAChE and bAChE is moderate, the binding pocket itself is highly conserved. The sequence in this region is $95 \%$ identical within a sphere of $10 \AA$ around the catalytic histidine (Hisact.) and the structures differ only slightly. This high conservation explains similar catalytic activities and identical enantiopreference. The major difference in both AChE structures is the orientation of the side chain of W86, which in the bAChE binding pocket is shifted by 1.5 $\AA$ towards the catalytic center, compared to eeAChE. Modeling of the complexes of both enantiomers of $\mathbf{3}$ with eeAChE and bAChE resulted in significant differences of the stability of the complexes under simulation conditions. While the preferred $(\boldsymbol{R}) \mathbf{- 3}$ enantiomer fitted well into the binding pocket of both enzymes, the nonpreferred (S)-3 enantiomer faced strong repulsive forces in bAChE, due to an interaction of the substrate's phenyl substituent with residue 686 (Figure 2). This repulsive interaction was not observed in the eeAChE-(S)-3 complex, which explains the experimentally observed higher enantioselectivity of bAChE.

\section{Protein engineering of BsubpNBE}

A similar modeling strategy was applied to BsubpNBE to explain enantiopreference and enantioselectivity, and to design mutants with improved enantioselectivity. The alcohol binding site of BsubpNBE is hydrophobic and 
nearly spherical at the bottom (Figure 3). Two opposite walls, the GGAX-loop and A400, limit this sphere. This is a feature that distinguishes the GGG(A)X-type hydrolases from the GX-type hydrolases where the corresponding residues form a steep wall that prevents the access of tertiary alcohols by blocking the binding of a third substituent in this direction. This sphere opens towards a large, hydrophobic gorge (Figure 4). A $4 \AA$ pocket, the hydrophobic dent, is composed of F313, L314 and A400. Towards the acyl binding tunnel it is terminated by the active histidine (Hisact, H399). The active site is almost open towards the solvent, except for a hydrophobic ridgeshaped loop (L67, L68) blocking the entrance in front of the GGAX-loop (Figure 3).

For both enantiomers of $\mathbf{3}$, the medium-sized ethinyl substituent is located in the hydrophobic dent. The bulky phenyl substituent is bound differently: for the preferred $(\boldsymbol{R}) \mathbf{- 3}$ enantiomer into the hydrophobic gorge (Figure 4A) and for the non-preferred (S)-3 to the spherical hydrophobic pocket near the hydrophobic ridge (Figure 4B). Both complexes were stable and showed a similar conformation, which explains the low enantioselectivity of BsubpNBE towards this substrate. To validate this model, mutants with improved enantioselectivity towards 3 were predicted. To increase enantioselectivity, a potential mutation should prevent 
binding of the non-preferred enantiomer or improve binding of the preferred enantiomer. Two promising residues for mutagenesis, A400 and G105, were identified. Replacing one of these amino acids by residues with a more space-demanding side chain was expected to complicate binding of (S)-3 by interaction of the residue's side chain with the substrate's phenyl substituent. Molecular dynamics (MD) simulations of BsubpNBE G105A indeed showed a rejection of the (S)-3 phenyl substituent and consequently a less favorable binding of the (S)-enantiomer (Figure 5, B1 and C1). Because of the proximity of G105 to the active s189 an exchange by an even more bulky residue than alanine was not possible without reducing the catalytic activity. In contrast, a substitution of A400 by isoleucine, leucine, valine, or phenylalanine had no effect on the (S)enantiomer. The size of the isoleucine, leucine and valine side chains were not sufficient to interfere with the substrate's phenyl substituent. The phenylalanine side chain, however, did not orient to the binding pocket but pointed towards other aromatic residues nearby. When the two enantiomers of 1 were docked to mutant G105A, modeling studies predicted a switch from $(R)$ - to (S)-preference. The computer model showed an increased interference of the small methyl substituent of the $(R)-$ enantiomer with the enlarged A105 residue, but no change 
in interaction with the $(S)$-enantiomer. This is in contrast to the results with $\mathbf{3}$ where the non-preferred (S)-enantiomer interacts with A105. The $(R)$-enantiomers of both substrates interact differently: for $(\boldsymbol{R}) \mathbf{- 1}$ the largest alkyl substituent is oriented into the hydrophobic dent; due to binding of this substituent to the wall of the hydrophobic dent, the methyl substituent comes closer to the A105 residue than observed with $(\boldsymbol{R})-\mathbf{3}$ (Figure 5) .

To validate simulation results, mutants BsubpNBE A400I, G105A, and double mutant A400I/G105A were generated and expressed in E. coli. Activity and enantioselectivity were determined and compared to the wild type enzyme. While mutation A400I barely changed expression and activity, G105A reduced activity of BsubpNBE towards $p$ nitrophenyl acetate (pNPA) to $10 \%$ of wild type activity. The double mutant showed no observable activity. As predicted by molecular modeling, enantioselectivity towards 3 was not changed by A400I, while mutation G105A lead to a 6-fold increase of enantioselectivity from $E=$ 3 (BsubpNBE WT) to $E=19$ (BsubpNBE G105A) (Table 1 ). Mutant G105A also showed the predicted inversion of enantiopreference towards 1: BsubpNBE WT preferred hydrolysis of the $(R)$-enantiomer with low enantioselectivity $(E=1.7)$, while the mutant BsubpNBE G105A favored the $(S)$-enantiomer $(E=4)$. Towards 
substrate 2, where BsubpNBE WT has been shown to be completely unselective, mutant G105A shows very low, but significant enantioselectivity $(E=1.3)$, preferring the (S)-enantiomer. Determination of enantioselectivity comprises two sources of error. The enantiomeric excess (ee) can be experimentally determined with high precision ( \pm 2\%) via gas chromatographic analysis. However, due to the approximations in the formula used to calculate enantioselectivity from ee values, ${ }^{[33]}$ the error margin for the E-values is about $10 \%$. Thus, although the value of $E$ is given with a 10 \% accuracy, the change from nonselective to low enantioselectivity can be identified at much higher reliability.

In the MD simulations the non-preferred enantiomer is pushed out of the optimal binding orientation as a consequence of repulsive interaction. This leads to an increase of the distance between the active histidine and the ester oxygen. Thus, the distance between the protonated $\mathrm{N}_{\varepsilon}$ of the Hisact and the ester oxygen Oester d. $\mathrm{N}_{\varepsilon} \mathrm{H}-\mathrm{O}_{\text {ester }}$ ) was taken as a geometrical probe to quantify effects on enantioselectivity (Figure 6). A small distance $d\left(\mathrm{~N}_{\varepsilon} \mathrm{H}-\mathrm{O}_{\text {ester }}\right)$ is necessary to ensure stabilization of the substrate complex and proton transfer during the catalytic cycle. The difference $\Delta \mathrm{d}\left(\mathrm{N}_{\varepsilon} \mathrm{H}-\mathrm{O}_{\text {ester }}\right)$ observed in the modeled complexes with the preferred and non- 
preferred enantiomer is a quantitative measure of the difference in activity towards both enantiomers, and thus to the experimentally determined enantioselectivity. Indeed, experimental E-values correlate well with $\Delta \mathrm{d}\left(\mathrm{N}_{\varepsilon} \mathrm{H}-\right.$ Oester) as derived from the computer model (Figure 7), and enantioselectivity can be predicted directly from MD simulations. 


\section{Discussion}

\section{Modeling enantioselectivity towards TAEs}

Using manual docking, relaxation by MD simulation, and geometric analysis a model was established to understand and predict enantioselectivity towards TAEs. The model identifies a geometric probe $\Delta \mathrm{d}\left(\mathrm{N}_{\varepsilon} \mathrm{H}-\mathrm{O}_{\text {ester }}\right)$, which is correlated to experimentally determined enantiopreference and enantioselectivity. A similar model has previously been applied to explain enantioselectivities of lipases towards chiral substrates like triacylglycerols and secondary alcohols. ${ }^{[10,}$ 15, 19, 20, 34] The results for secondary alcohols are in accordance with complementary methods which model enantioselectivity in hydrolasecatalyzed reactions by evaluating the free energy of enzyme-substrate complexes. [21, 35]

\section{Small changes in structure lead to small changes in enantioselectivity}

Intuitively, one would expect that homologous enzymes have identical enantiopreference as it was observed for AChEs from different organisms where differences in sequence led to changes in $E$ values but not to a reversal of enantiopreference. However, this rule cannot be generalized, as it has been shown previously for two homologous lipases from Rhizopus oryzae and Rhizomucor miehei where small structural changes led to opposite 
stereopreference towards triacylglycerols. ${ }^{[19]}$ A switch of enantiopreference between two similar enzymes could also explain our observation that two commercial PLE preparations (chirazyme E-1 and E-2) have opposite enantiopreference towards $\mathbf{1}$. This is most probably caused by the different composition of both PLE fractions, as it has been demonstrated that commercial PLE preparations frequently contain several hydrolytic enzymes ${ }^{[36]}$ and isoenzymes. ${ }^{[37]}$ This may result not only in an opposite enantiopreference of two preparations, but also in an apparent enantioselectivity which is much lower than for the individual purified isoenzyme. ${ }^{[38]}$

\section{Switch in enantiopreference}

Changing the enantiopreference of a biocatalyst is still a challenge. In asymmetric organic synthesis a switch of the handedness of the reaction can be achieved by an exchange of the chiral auxiliary by its enantiomeric counterpart (i.e. by switching from L- to D-tartrate in the Sharpless-epoxidation ${ }^{[39]}$ ). In biocatalysis, this inversion of the enantiotopic surrounding corresponds to an exchange of the natural L-enzyme by a chemically synthesized D-enzyme as it has been demonstrated for HIV protease. ${ }^{[40]}$ Interestingly a switch in enantiopreference of a biocatalyst can sometimes be obtained with only small changes of sequence and structure. Towards 
substrate 1, a single mutation in BsubpNBE led to a switch from $(R)$-preference of the wild type enzyme to (S)-preference of the mutant G105A. The model predicted, that due to the mutation, the orientation of the substrate changed: the now preferred $(S)$-enantiomer binds with the smallest (methyl-) substituent to the hydrophobic gorge, while in the wild-type enzyme the largest substituent is oriented into this huge binding pocket. In contrast, substrate $\mathbf{3}$ binds in a similar orientation to wild-type and mutant. Thus, small changes in the shape of the binding site have opposite effects on different substrates. Therefore, a generally valid empirical rule, which predicts the preferred enantiomer only from the structure of the substrate, is not feasible for tertiary alcohols. This distinguishes enantiorecognition of tertiary and secondary alcohols as the latter bind in a similar conformation to the lipase binding site and thus enantiopreference can be predicted by a simple and general rule. ${ }^{[16,17]}$

Changes of enantiopreference by point mutations in the substrate binding site have also been observed for lipases, ${ }^{[15]}$ phosphotriesterases, ${ }^{[41]}$ lactate dehydrogenases, ${ }^{[42]}$ and alcohol dehydrogenases. [43] Thus, our results support the general idea that enantiopreference is not an inherent property of an enzyme but can be tuned by protein engineering. A switch of enantiopreference by 
point mutations was also achieved by directed evolution experiments. ${ }^{[13,44]}$ Since mutations were far away from the

substrate binding site, their effect on enantiorecognition is still obscure. These long-range effects indicate that there might be further effects of mutations like changing the overall structure of the protein or its dynamics. ${ }^{[45]}$

The successful change in enantiopreference and enantioselectivity by the single mutation G105A in BsubpNBE demonstrates that this site is a major determinant in enantiorecognition, since it imposes sterical restrains to the shape of the substrate near its stereo center. This is further underlined by comparing the effect of two single mutations to a double mutation. Although A400 and G105 are situated at opposite sides of the binding site, their effect on activity is highly synergetic. While the exchange A400I had no effect on enzyme activity and mutant G105A still had $10 \%$ of wild type activity, a combination of both mutations completely inactivated the enzyme (< 0.1 of wild type activity). The relevance of G105 is also underlined by the observation that, as first residue of the GGG(A)Xmotif, ${ }^{[27]}$ it is highly conserved in all carboxylesterases. The only exception is an $\alpha$-esterase from Drosophila buzzatii where it is replaced by a proline. ${ }^{[46]}$ However, mutation G105P in BsubpNBE resulted 
in a substantial loss of activity $(<1 \%$ of wild type activity, data not shown), also proving that the enzyme does not tolerate considerable changes in this region.

\section{Enhancing enantioselectivity}

While mutation G105A in BsubpNBE led to a switch in enantiopreferences towards substrate 1, enantiopreference towards substrate $\mathbf{3}$ did not switch. Instead the model predicted a considerable increase in enantioselectivity towards substrate $\mathbf{3}$, which was experimentally confirmed. An enantioselectivity of $E=19$ is an appropriate starting point for further improvement of enantioselectivity by standard methods like substrate engineering, solvent modification, enzyme immobilization or temperature and $\mathrm{pH}$ changes, up to a level which is suitable for industrial applications.

\section{Conclusion}

Our findings show that the effect of a side chain replacement can not be generalized to all substrates, but has to be considered for each substrate-enzyme pair independently. Since the conformations of the two enantiomers in the binding site depend on the details of the structure of substrate and enzyme, the effect of mutants is personalized. Thus the same mutation G105A can 
lead to a switch of enantiopreference (substrate 1), generation of enantiorecognition (substrate 2), and six fold increase in enantioselectivity (substrate $\mathbf{3}$ ). The effect of mutations depends on differences in the interaction with both enantiomers: if the mutant primarily blocks the binding of the non-preferred enantiomer enantioselectivity is increased, if it blocks binding of the preferred enantiomer enantioselectivity is decreased or even reversed.

Thus enantiorecognition by esterases can be explained on a molecular level by careful investigation of the interactions between enzyme and substrate. From a quantitative model of enantioselectivity, personalized mutants with useful properties towards individual substrates can be predicted. 


\section{Experimental section}

General: Chemicals were purchased from Fluka (Buchs Switzerland) or Sigma (Deisenhofen, Germany) at highest purity available. PLE (Chirazyme E1 and E2) were purchased from Roche (Mannheim, Germany), CRL-CLEC from Altus (Cambridge, MA), eeAChE from Sigma. NMR experiments were performed on a Bruker 500 MHz device.

Cloning of hydrolases: Genomic DNA from Bacillus subtilis DSM 402 was isolated using a standard protocol. [47] BsubpNBE was cloned by amplification of the described $\mathrm{ORF}^{[48]}$ out of the genomic DNA using primers 5'- ACT ACT ACT ACT CAT ATG ACT CAT CAA ATA GTA ACG -3' and 5'- CTA CtA cta ctA GGA tCC tTC tCC tTt tGA AgG-3'. The PCR product was digested using restriction endonucleases BamHI and NdeI and was ligated into a expression vector yielding the plasmid pG-BsubpNBE.WT.

Protein expression system: p-Nitrobenzyl esterase from Bacillus subtilis and variants were expressed in E. coli. The encoding genes were in plasmids (pG-BsubpNBE) under control of a rhamnose inducible promoter, rhaP. [11, 49] bAChE and hAChE were expressed in Pichia pastoris as published and kindly provided as crude, non-lyophilized extracts by S. Vorlová for investigation. [50]

\section{Cell transformation, grows and protein expression:}

Competent E. coli DH5 $\alpha$ cells were prepared using the TSS method, and transformed using a standard protocol. [11, 51] 
The transformed cells were plated on LB agar plates (containing $100 \mathrm{mg} / \mathrm{mL}$ ampicillin) .

For protein expression $5 \mathrm{~mL}$ of LB-amp broth (containing $100 \mathrm{mg} / \mathrm{mL}$ ampicillin) was inoculated with a single colony of recombinant $\mathrm{DH} 5 \alpha$ and incubated overnight at $37{ }^{\circ} \mathrm{C}$. The overnight culture was diluted 1:1000 in fresh LB-amp broth, and cells were allowed to grow until OD 600 0.5-0.7, before $1 \div(\mathrm{v} / \mathrm{V})$ of sterile rhamnose solution $(200 \mathrm{~g} / \mathrm{l})$ was added for induction. Cells were incubated again for at least $8 \mathrm{~h}$ at $37{ }^{\circ} \mathrm{C}$. Cells were collected by centrifugation, washed two times with sodium phosphate buffer (50 mM, pH 7.5) and resuspended in the same buffer for cell lysis by sonification. To remove cell debris, the solution was centrifuged again, and the supernatant was lyophilized yielding the enzyme crude extract.

Site directed mutagenesis: site directed mutagenesis was performed using the "QuikChange"-method (Stratagene, La Jolla, CA): complementary primers bearing the nucleotides to be changed were used in a PCR. Synthesis time was elongated to $8 \mathrm{~min}$ to ensure amplification of the complete plasmid. The PCR mixture was treaded afterwards with DpnI to digest the non methylated template DNA. Transformation and selection of recombinant cells was performed as described above.

Synthesis of tertiary alcohol acetates: Linalyl acetate $\mathbf{1}$ was derived from Fluka (Buchs, Switzerland). 
(R/S)-2-Phenyl-3-butin-2-yl acetate 3: In $300 \mathrm{~mL}$ freshly distilled, dried THF $25 \mathrm{~g}$ (R/S)-2-phenyl-3-butin-2-ol (171 mmol) was dissolved. The solution was cooled on ice before $80 \mathrm{~mL}$ of BuLi in toluene $(2.5 \mathrm{M}, 200 \mathrm{mmol})$ was added drop wise over a period of 10 min. The mixture was stirred another $15 \mathrm{~min}$ and $15 \mathrm{~mL}$ freshly distilled acetyl chloride $(211 \mathrm{mmol})$ was added. After removing the ice bath, the mixture was heated under reflux for $1 \mathrm{~h}$. It was again cooled down to ambient temperature and nonconverted acetyl chloride was hydrolyzed by adding $150 \mathrm{~mL}$ water. The mixture was extracted three times with $300 \mathrm{~mL}$ diethyl ether, the collected organic phases were dried with anhydrous $\mathrm{Na}_{2} \mathrm{SO}_{4}$ before the solvent was removed in vacuum. Distillation $\left(114{ }^{\circ} \mathrm{C}, \quad 15\right.$ mbar $)$ yielded the product as a colorless liquid (24,4 g; $130 \mathrm{mmol} ; 76$ \%). ${ }^{1} \mathrm{H}-\mathrm{NMR}\left(500,15 \mathrm{MHz} ; \delta\right.$ in ppm vs. TMS; in $\left.\mathrm{CDCl}_{3}\right) \delta: 1,89$ (3 $\mathrm{H} ; \mathrm{s}) ; 2,07(3 \mathrm{H} ; \mathrm{s}) ; 2,80(1 \mathrm{H} ; \mathrm{s}) ; 7,34(1 \mathrm{H}) ; 7,36$ (2 $\mathrm{H}) ; 7,58(2 \mathrm{H})$

${ }^{13} \mathrm{C}-\mathrm{NMR}\left(125,76 \mathrm{MHz} ; \delta\right.$ in ppm vs. TMS; in $\left.\mathrm{CDCl}_{3}\right) \delta: 21,71 ;$ 32,$05 ; \quad 75,31 ; \quad 75,56 ; 124,75 ; 124,84 ; 127,91 ; 128,33 ;$ 128,$38 ; 142,10 ; 168,62$

(R/S)-3-Methyl-1-pentin-3-yl acetate 2: To $17 \mathrm{~mL}(R / S)-3-$ methyl-1-pentin-3-ol (14.8 9, $150 \mathrm{mmol}), 17 \mathrm{~mL}$ acetic anhydride (18.4 g, $180 \mathrm{mmol})$ were added drop wise, while the flask was cooled in an ice bath. After adding $50 \mathrm{mg}$ 
phosphorus pentoxide and stirring for another $15 \mathrm{~min}$, the ice bath was removed and the mixture was stirred at ambient temperature for $16 \mathrm{~h}$. The solution was washed twice with $100 \mathrm{~mL}$ water and extracted two times with 100 mL diethyl ether. The organic layers were combined and washed with saturated $\mathrm{NaHCO}_{3}$ solution until no formation of $\mathrm{CO}_{2}$ was observed. They were washed again twice with water and dried over anhydrous $\mathrm{Na}_{2} \mathrm{SO}_{4}$ before the solvent was removed. Flash chromatography on silica gel (petrol ether:ethyl acetate 4:1) yielded the product as a colorless liquid $(17,65 \mathrm{~g} ; 126 \mathrm{mmol} ; 84$ 으.

${ }^{1} \mathrm{H}-\mathrm{NMR} \quad\left(500,15 \mathrm{MHz} ; \delta\right.$ in ppm vs. TMS; in $\left.\mathrm{CDCl}_{3}\right) \delta: 1,03$ (3 $\mathrm{H} ; \mathrm{t} ; \mathrm{J}=7,5) ; 1,66(3 \mathrm{H} ; \mathrm{s}) ; 1,85(1 \mathrm{H} ; \mathrm{m}) ; 1,96(1 \mathrm{H}$; $\mathrm{m}) ; 2,03(3 \mathrm{H} ; \mathrm{s}) ; 2,55(1 \mathrm{H} ; \mathrm{s})$

${ }^{13} \mathrm{C}-\mathrm{NMR} \quad\left(125,76 \mathrm{MHz} ; \delta\right.$ in ppm vs. TMS; in $\left.\mathrm{CDCl}_{3}\right) \delta: 8,40$; 21,$89 ; 25,90 ; 34,67 ; 73,18 ; 75,31 ; 83,75 ; 169,42$

\section{Biotransformation:}

Reactions were either performed using a pH-stat system for conversion control (BsubpNBE) or in $2 \mathrm{~mL}$ reaction tubes for faster screening (CRL, AChEs).

\section{pH-stat :}

A aqueous emulsion of the substrate ester (10 mM) was prepared using gum arabic (2 \% w/v) in an ultra turrax. $20 \mathrm{~mL}$ of the emulsion were thermostated at $40{ }^{\circ} \mathrm{C}$ in the $\mathrm{pH}$ stat's reaction chamber. The reaction was started by 
adding the enzyme $(10 \mathrm{mg})$. $\mathrm{pH}$ was kept constant by automated titration with $0.1 \mathrm{M} \mathrm{NaOH}$. At selected points of hydrolysis, determined by the amount of consumed $\mathrm{NaOH}$, samples $(200 \mu \mathrm{L})$ were withdrawn from the reaction mixture and extracted with toluene $(250 \mu \mathrm{L})$. These were analyzed using GC separation on a chiral phase (Heptakis-(6-0pentyl-2,3-di-0-methyl)- $\beta$-cyclodextrin in ov 1701 (Prof. König, University of Hamburg, Germany); Carrier: $\mathrm{H}_{2} 40$ $\mathrm{kPa})$.

In contrast to the other tested substrates, 3 showed significant autohydrolysis. This hydrolysis of $\mathbf{3}$ occurs via a $\mathrm{S}_{\mathrm{N}} 1$ type mechanism ${ }^{[25]}$ and shows only minor $\mathrm{pH}-$ dependence between $\mathrm{pH} 6.0$ and 8.5 where a suitable enzyme activity was observed. Lowest autohydrolysis rates were near neutral pH. It was decided to carry out measurements at $\mathrm{pH}$ 7.5, where autohydrolysis is only slightly higher than at pH 7.0 but higher enzyme activity is ensured. Enzymes were added in amounts to ensure that 50 \% conversion were reached within less than 20 min, thus guarantying that autohydrolysis contributes to less than 5 of the total conversion. For reactions with low catalytic activity and moderate or high enantioselectivity, however, autohydrolysis might reach similar levels as the enzymatic conversion of the nonpreferred enantiomer. As a result, the observed 
enantioselectivity would be slightly lower than the actual enantioselectivity of the enzymatic reaction.

\section{Molecular modeling:}

Hard- and software: Molecular modeling was performed on a Silicon Graphics Octane 2 workstation (SGI, Montain View, CA) using Sybyl 6.1 (Tripos, St. Louis, MO). For all calculations the Tripos force field and Gasteiger-Hückel charges were used. The partial charges of Hisact. and the tetrahedral Seract.-substrate complex were assigned as described previously [52]

Structures: Experimentally determined X-ray structures of CRL (PDB entry 1LPM) ${ }^{[16]}$, eeAChE (1C2B $)^{[30]}$, and hAChE $(2 \mathrm{CLJ})^{[31]}$ were retrieved from the Protein DataBank. A homology model of BsubpNBE DSM 402 was created using the X-ray structures of the corresponding enzyme from the strain NRRL B8079 (1QE3, 1C7J, 1C7I). ${ }^{[53]}$ The homology model for bAChE is based on the structure of AChE from Torpedo californica (1QIK, 1CFJ). ${ }^{[32]}$ The homology models were computed using the Swiss-Model automated modeling service of GlaxoSmithKline (http://www.expasy.ch /swissmod/SWISS-MODEL.html) [54] $^{[54}$

All solvent molecules in the PDB files were removed before substrate docking. Substrates were manually docked into the binding site of the enzymes, mimicking the 
tetrahedral intermediate formed after the nucleophilic attack of the Seract., which resembles the rate limiting step of ester hydrolysis. The substrate was oriented with the oxyanion towards the oxyanion hole residues and the protonated $\mathrm{N}_{\varepsilon}$ embedded between the $\mathrm{O}_{\gamma}$ and the Oester of the substrate. [52] The substrate's substituents were oriented in the binding pocket to a minimum of repulsive interaction with the protein structure.

Molecular dynamics simulations: The enzyme-substrate complex was optimized by minimization and subsequent MD simulations for 18 ps $(2$ ps at $5 \mathrm{~K}, 2$ ps at $30 \mathrm{~K}, 2$ ps at $70 \mathrm{~K}, 12 \mathrm{ps}$ at $100 \mathrm{~K})$. The temperature coupling constant was adjusted to $10 \mathrm{fs}$. The non-bonded interaction cutoff was set to $8 \AA$, the dielectric constant to 1.0. The conformers were saved every $40 \mathrm{fs}$. Conformers of the last 2 ps were averaged and used for analysis. All minimization and MD simulations were performed in vacuo with constrained protein backbone.

To verify that results do not depend on the initial conformation or the simulation time, additional simulations with slightly different initial conformations and extenden simulation times (100 ps) were performed. In all cases the system reproducibly relaxed to a similar conformation. 


\section{Acknowledgements}

The authors gratefully acknowledge Dr. Sandra Vorlová for providing recombinant $b A C h E$ and $h A C h E$ and Volker Nödinger for DNA sequencing. This work was supported by the Deutsche Forschungsgemeinschaft (Bo 1475/2-1) and the Bundesministerium für Bildung und Forschung (project PTJ $31 / 0312702)$. 


\section{References}

[1] U. T. Bornscheuer, R. J. Kazlauskas, Hydrolases in Organic Synthesis, 1 ed., Wiley-VCH, Weinheim, 1999.

[2] a) A. Liese, K. Seelbach, C. Wandrey, Industrial Biotransformations, Wiley-VCH, Weinheim, 2001; b) K. Faber, Biotransformations in organic Chemistry, 4 ed. , Springer-Verlag, Berlin, 1999.

[3] D. L. Ollis, E. Cheah, M. Cygler, B. Dijkstra, F. Frolow, S. M. Franken, M. Harel, S. J. Remington, I. Silman, J. Schrag, et al., Protein Eng. 1992, 5, $197-211$

[4] a) P. Carter, J. Wells, Nature 1988, 322, 564-568; b) J. D. Schrag, Y. G. Li, S. Wu, M. Cygler, Nature 1991, 351, 761-764.

[5] a) M. Holmquist, Chem. Phys. Lipids 1998, 93, 57-66;

b) T. Wagegg, M. M. Enzelberger, U. T. Bornscheuer, R. D. Schmid, J. Biotechnol. 1998, 61 .

[6] a) F. Björkling, J. Boutelje, Gatenbeck, K. Hult, T. Norin, Tetrahedron Lett. 1986, 26, 4957; b) G. Guanti, L. Banfi, E. Narisano, R. Riva, S. Thea, Tetrahedron Lett. 1986, 27, 4639-4642.

[7] N. Krebsfanger, K. Schierholz, U. T. Bornscheuer, J. Biotechnol. 1998, 60, 105-111.

[8] E. Keinan, E. K. Hafeli, K. K. Seth, L. R., J. Am. Chem. Soc. 1986, 108, 162 . 
[9] A. M. Klibanov, Trends Biotechnol. 1997, 15, 97-101.

[10] U. H. Kahlow, R. D. Schmid, J. Pleiss, protein Sci. 2001, 10, 1942-1952.

[11] E. Henke, U. T. Bornscheuer, Biol. Chem. 1999, 380, 1029-1033.

[12] K. E. Jaeger, T. Eggert, A. Eipper, M. T. Reetz, Appl. Microbiol. Biotechnol. 2001, 55, 519-530.

[13] D. Zha, S. Wilensek, M. Hermes, K. E. Jaeger, M. T. Reetz, Chemical Communications 2001, 24, 2664-2665.

[14] a) F. Manetti, D. Mileto, F. Corelli, S. Soro, C. Palocci, E. Cernia, I. D'Acquarica, M. Lotti, L. Alberghina, M. Botta, Biochim. Biophys. Acta 2000; b) 1543, 146-158; D. Rotticci, J. C. RotticciMulder, S. Denman, T. Norin, K. Hult, Chembiochem 2001, 2, 766-770.

[15] H. Scheib, J. Pleiss, P. Stadler, A. Kovac, A. P. Potthoff, L. Haalck, F. Spener, F. Paltauf, R. D. Schmid, Protein Eng. 1998, 11, 675-682.

[16] M. Cygler, P. Grochulski, R. J. Kazlauskas, J. D. Schrag, F. Bouthilier, B. Rubin, A. N. Serreqi, A. K. Gupta, J. Am. Chem. Soc. 1994, 116, 3180 .

[17] R. J. Kazlauskas, A. N. E. Weissfloch, A. T. Rappaport, L. A. Cuccia, J. Org. Chem. 1991, 56, $2656-2665$.

[18] a) F. Carriere, E. Rogalska, C. Cudrey, F. Ferrato, R. Laugier, R. Verger, Bioorg. Med. Chem. 1997, 5, 
429-435; b) A. N. E. Weissfloch, R. J. Kazlauskas, J. org. Chem. 1995, 60, 6959-6969.

[19] H. Scheib, J. Pleiss, A. Kovac, F. Paltauf, R. D. Schmid, Protein Sci. 1999, 8, 215-221.

[20] T. Schulz, J. Pleiss, R. D. Schmid, Protein Sci. 2000, 9, 1053-1062.

[21] S. Raza, L. Fransson, K. Hult, Protein Sci. 2001, $10,329-338$.

[22] a) E. J. Corey, A. Guzman-Perez, Angew. Chem. Int. Edit. 1998, 37, 388-401, Angew. Chem. 1998, 110, 402-415; b) Christoffers, J. , A. Mann, Angew. Chem. Int. Edit. 2001, 40, 4591-4597, Angew. Chem. 2001, $113,4725-4732$.

[23] R. D. Schmid, R. Verger, Angew. Chemie Int. Ed. 1998, 37, 1608-1633, Angew. Chem. 1998, 110, 16941720.

[24] a) A. Schlacher, T. Stanzer, I. Osprian, M. Mischitz, E. Klingsbichel, K. Faber, H. Schwab, J. Biotechnol. 1998, 62, 47-54; b) D. O’Hagan, N. A. Zaidi, J. Chem. Soc. Perkin Trans. 1 1992, 8, 947949.

[25] D. O’Hagan, N. A. Zaidi, Tetrahedron: Asymmetry 1994, 5, 1111-1118.

[26] E. Henke, J. Pleiss, U. T. Bornscheuer, Angew. Chem. Int. Ed. 2002, 41, 3211-3213, Angew. Chem. 114, $3338-3340$. 
[27] J. Pleiss, M. Fischer, M. Peiker, C. Thiele, R.-D. Schmid, J. Mol. Catal. B: Enzym. 2000, 10, 491-508.

[28] a) A. Ordentlich, D. Barak, C. Kronman, N. Ariel, Y. Segall, B. Velan, A. Shafferman, J. Biol. Chem. 1998, 273, 19509-19517; b) A. K. Whiting, W. L. Peticolas, Biochemistry 1994, 33, 552-561; c) P. Bryan, M. W. Pantoliano, S. G. Quill, H. Y. Hsiao, T. Poulos, Proc. Natl. Acad. Sci. USA 1986, 83, $3743-3745$

[29] Y. Hotta, S. Ezaki, H. Atomi, T. Imanaka, Appl. Environ. Microbiol. 2002, 68, 3925-3931.

[30] Y. Bourne, J. Grassi, P. E. Bougis, P. Marchot, J. Biol. Chem. 1999, 274, 30370-30376.

[31] C. E. Felder, S. A. Botti, S. Lifson, I. Silman, J. L. Sussman, J. Mol. Graph. Model. 1997, 15, 318-327, $335-317$.

[32] C. B. Millard, G. Kryger, A. Ordentlich, H. M. Greenblatt, M. Harel, M. L. Raves, Y. Segall, D. Barak, A. Shafferman, I. Silman, J. L. Sussman, Biochemistry 1999, 38, 7032-7039.

[33] C. Chen, Y. Fujimoto, G. Girdaukas, C. J. Sih, J. Am. Chem. Soc. 1982, 104, 7294-7299.

[34] T. Schulz, R. D. Schmid, J. Pleiss, J. Mol. Model. 2001, 7, 265-270.

[35] a) F. Haeffner, T. Norin, K. Hult, Biophys. J. 1998, 74, 1251-1262; b) J. Ottosson, J. C. Rotticci- 
Mulder, D. Rotticci, K. Hult, Protein Sci. 2001, 10, $1769-1774$.

[36] D. Farb, W. P. Jencks, Arch. Biochem. Biophys. 1980, $203,214-226$.

[37] a) D. Seebach, M. Eberle, Chimia 1986, 40, 315 -318; b) W. Junge, E. Heymann, Eur. J. Biochem. 1979, 95, 519-525; C) E. Heymann, W. Junge, Eur. J. Biochem. 1979, 95, 509-518.

[38] A. Musidlowska, S. Lange, U. T. Bornscheuer, Angew. Chem. Int. Ed., 2001, 40, 2851-2853, Angew. Chem., 2001, 113, 2934-2936.

[39] a) T. Katsuki, K. B. Sharpless, J. Am. Chem. Soc. 1980, 102, 5974-5976; b) L. D. L. Lu, R. A. Johnson, M. G. Finn, K. B. Sharpless, J. org. Chem. 1984, 49, 728-731.

[40] R. C. Milton, S. C. Milton, S. B. Kent, Science 1992, 256, 1445-1448.

[41] a) M. Chen-Goodspeed, M. A. Sogorb, F. Wu, S. B. Hong, F. M. Raushel, Biochemistry 2001, 40, 13251331; b) M. Chen-Goodspeed, M. A. Sogorb, F. Wu, F. M. Raushel, Biochemistry 2001, 40, 1332-1339.

[42] H. K. W. Kallwass, J. K. Hogan, E. L. A. Macfarlane, V. Martichonok, W. Parris, C. M. Kay, M. Gold, J. B. Jones, J. Am. Chem. Soc. 1992, 114, 10704-10710.

[43] A. E. Tripp, D. S. Burdette, J. G. Zeikus, R. S. Phillips, J. Am. Chem. Soc. 1998, 120, 5137-5141. 
[44] O. May, P. T. Nguyen, F. H. Arnold, Nat. Biotechnol. 2000, 18, 317-320.

[45] a) L. Zidek, M. V. Novotny, M. J. Stone, Nat. Struct. Biol. 1999, 6, 1118-1121; b) J. L. Radkiewicz, H. Zipse, S. Clarke, K. N. Houk, J. Am. Chem. Soc. 2001, 123, 3499-3506; c) M. J. Osborne, J. Schnell, S. J. Benkovic, H. J. Dyson, P. E. Wright, Biochemistry 2001, 40, 9846-9859.

[46] G. C. d. Q. Robin, C. Claudianos, R. J. Russell, J. G. Oakeshott, J. Mol. Evol. 2000, 51, 149-160.

[47] P. Lebaron, J. F. Ghiglione, C. Fajon, N. Batailler, P. Normand, FEMS Microbiol. Lett. 1998, 160, 137143.

[48] a) F. Kunst, N. Ogasawara, I. Moszer, A. M. Albertini, G. Alloni, V. Azevedo, M. G. Bertero, P. Bessieres, A. Bolotin, S. Borchert, R. Borriss, L. Boursier, A. Brans, M. Braun, S. C. Brignell, S. Bron, S. Brouillet, C. V. Bruschi, B. Caldwell, V. Capuano, N. M. Carter, S. K. Choi, J. J. Codani, I. F. Connerton, A. Danchin, et al., Nature 1997, 390, 249-256; b) J. Zock, C. Cantwell, J. Swartling, R. Hodges, T. Pohl, K. Sutton, P. Rosteck, D. McGilvray, S. Queener, Gene 1994, 151, 37-43.

[49] I. Pelletier, J. Altenbuchner, Microbiology 1995, $141,459-468$. 
[50] a) S. Minning, A. Serrano, P. Ferrer, C. Sola, R. D. Schmid, F. Valero, J. Biotechnol. 2001, 86, 59-70; b) S. Vorlová, J. Schmitt, R. D. Schmid, 2003, submitted.

[51] J. Sambrook, E. F. Fritsch, T. Maniatis, Molecular cloning: a laboratory manual, Cold spring Harbor Laboratory Press, Cold Spring Harbor, N. Y., 1989.

[52] H.-C. Holzwarth, J. Pleiss, R.-D. Schmid, J. Mol. Catal. B: Enzym. 1997, 3, 73-82.

[53] B. Spiller, A. Gershenson, F. H. Arnold, R. C. Stevens, Proc. Natl. Acad. Sci. USA 1999, 96, 1230512310.

[54] N. Guex, M. C. Peitsch, Electrophoresis 1997, 18, $2714-2723$ 


\section{Legends}

Figure 1: Model substrates used in the experiments and in molecular modeling.

Figure 2: Orientation of $\mathbf{6} 86$ in the binding pockets of eeAChE (gray) and bAChE (black). Displayed are the active S203 (gray) of eeAChE and the covalently bound nonpreferred (S)-3 (light gray). In bAChE, the W86 side chain moves by $1.5 \AA$ towards the substrate compared to eeAChE, due to interactions with its neighbor M85 (not shown) .

Figure 3: Binding mode of (S)-3 to BsubpNBE; the distinct binding pockets are indicated.

Figure 4: Binding pocket of BsubpNBE wild type $(\mathrm{a}, \mathrm{b})$ and mutant G105A (c,d) in complex with $(\boldsymbol{R})-\mathbf{3}(\mathrm{a}, \mathrm{c})$ and $(\boldsymbol{S}) \mathbf{- 3}$ (b, d). Hisact (H399) and the hydrophobic ridge (L67 and L68) are shown in a.

Figure 5: Binding of substrates $\mathbf{2}$ and $\mathbf{3}$ in the binding pocket of BsubpNBE WT and BsubpNBE G105A. The protein surface is colored according to the hydrophobicity of the residues. G105 in BsubpNBE WT and A105 in the mutant are colored yellow. For better clarity, hydrogen atoms are 
not displayed. A: WT with preferred substrate enantiomers (A1:(S)-3; A2:(R)-1). B: WT with non-preferred substrate enantiomers (B1:(S)-3; B2:(R)-1). C: mutant G105A with non-preferred substrate enantiomers (C1:(S)-3 C2:(S)-1).

Figure 6: Tetrahedral intermediate: The substrate ester is covalently bound to the Seract. The anionic intermediate formed is stabilized by hydrogen bonds to the oxyanion hole residues. The complex shown was used for modeling studies. The distance between the $\mathrm{N}_{\varepsilon}$ proton and the oxygen of the ester bond $\left(\mathrm{d}\left(\mathrm{N}_{\varepsilon} \mathrm{H}-\mathrm{O}_{\text {ester }}\right)\right)$ is indicated. The difference between the distances observed by modeling of the enzyme complexes with both enantiomers $\left(\Delta \mathrm{d}\left(\mathrm{N}_{\varepsilon} \mathrm{H}-\mathrm{O}_{\text {ester }}\right)\right)$, can be used as parameter indicating the enantioselectivity.

Figure 7: Correlation of modeling data $\left(\Delta \mathrm{d}\left(\mathrm{N}_{\varepsilon} \mathrm{H}-\mathrm{O}_{\text {ester }}\right)\right)$ and experimental results $(E=$ ratio $R / S)$; enantioselectivity of BsubpNBE wild type (open symbols) and mutant G105A (solid symbols) towards linalyl acetate $\mathbf{1}(\bullet), 3$-methyl1-pentin-3-yl acetate 2 (s), and 2-phenyl-3-butin-2-yl acetate $\mathbf{3}$ 
Table 1: Enantioselectivity of GGG(A)X-type hydrolases towards TAEs.

\begin{tabular}{|c|c|c|c|c|}
\hline Enzyme & Substrate & Time & Conv. [\%] & $E^{\text {d) }}$ \\
\hline \multirow{3}{*}{$\begin{array}{l}\text { PLE E1, } \\
10 \mathrm{mg}^{\prime} \\
390 \mathrm{U}^{\mathrm{a})}\end{array}$} & 1, $50 \mu \mathrm{mol}$ & $8 \mathrm{~h}$ & 48 & $1.5 \quad(R)$ \\
\hline & 2, $50 \mu \mathrm{mol}$ & $2 \mathrm{~h}$ & 53 & $4 \quad(S)$ \\
\hline & 3, $200 \mu \mathrm{mol}, 440 \mathrm{U}$ & $32 \mathrm{~min}$ & 50 & $1.3(R)$ \\
\hline \multirow{3}{*}{$\begin{array}{l}\text { PLE E2, } \\
10 \mathrm{mg}, \\
270 \mathrm{U}^{\mathrm{a})}\end{array}$} & 1, $50 \mu \mathrm{mol}$ & $4 \mathrm{~h}$ & 42 & $1.7 \quad(S)$ \\
\hline & 2, $50 \mu \mathrm{mol}$ & $2 h$ & 69 & $4 \quad(S)$ \\
\hline & 3, $200 \mu \mathrm{mol}$ & $21 \mathrm{~min}$ & 50 & $5 \quad(R)$ \\
\hline \multirow[t]{3}{*}{$\begin{array}{l}\mathrm{bAChE}, \\
100 \quad \mathrm{U}^{\mathrm{b})}\end{array}$} & 1, $50 \mu \mathrm{mol}$ & $48 \mathrm{~h}$ & 6 & $1.1 \quad(S)$ \\
\hline & 2, $50 \mu \mathrm{mol}$ & $4 \mathrm{~h}$ & 25 & $7 \quad(S)$ \\
\hline & 3, $50 \mu \mathrm{mol}$ & $1 \mathrm{~h}$ & 48 & $10(R)$ \\
\hline \multirow[t]{3}{*}{$\begin{array}{l}\text { eeAChE, } \\
100 \mathrm{U}^{a)}\end{array}$} & $\mathbf{1}, 50 \mu \mathrm{mol}$ & $48 \mathrm{~h}$ & 10 & $1.5 \quad(S)$ \\
\hline & 2, $50 \mu \mathrm{mol}$ & $24 \mathrm{~h}$ & 26 & $4 \quad(S)$ \\
\hline & 3, $50 \mu \mathrm{mol}$ & $4 \mathrm{~h}$ & 50 & $4 \quad(R)$ \\
\hline \multirow[t]{3}{*}{$\begin{array}{l}\text { hAChE, } \\
37.5 \mathrm{U}^{\mathrm{b})}\end{array}$} & 1, $50 \mu \mathrm{mol}$ & $48 \mathrm{~h}$ & 5 & $1.1(S)$ \\
\hline & 2, $50 \mu \mathrm{mol}$ & $24 h$ & 17 & $3(S)$ \\
\hline & 3, $50 \mu \mathrm{mol}$ & $4 \mathrm{~h}$ & 39 & $3(R)$ \\
\hline \multirow{3}{*}{$\begin{array}{l}\text { CLEC- } \\
\text { CRL, } \\
10 \mathrm{mg}\end{array}$} & 1,50 umol & $8 \mathrm{~h}$ & 23 & 1.0 \\
\hline & 2, $50 \mu \mathrm{mol}$ & $2 \mathrm{~h}$ & 56 & $2(S)$ \\
\hline & 3, $50 \mu \mathrm{mol}$ & $30 \mathrm{~min}$ & 77 & 1.0 \\
\hline \multirow{3}{*}{$\begin{array}{l}\text { BsubpNBE } \\
\text { WT, } \\
10 \mathrm{mg} \\
350 \mathrm{U}^{\mathrm{C})}\end{array}$} & $\mathbf{1}, 200 \mu \mathrm{mol}$ & $38 \mathrm{~min}$ & 50 & $1.7 \quad(R)$ \\
\hline & 2, $200 \mu \mathrm{mol}$ & $49 \mathrm{~min}$ & 50 & 1.0 \\
\hline & 3, $200 \mu \mathrm{mol}$ & $20 \mathrm{~min}$ & 50 & $3(R)$ \\
\hline \multirow{3}{*}{$\begin{array}{l}\text { BsubpNBE } \\
\text { A } 400 \mathrm{I}, \\
10 \mathrm{mg} \\
230 \mathrm{U}^{\mathrm{C})}\end{array}$} & 1, $200 \mu \mathrm{mol}$ & $27 \mathrm{~min}$ & 50 & $2(R)$ \\
\hline & 2, $200 \mu \mathrm{mol}$ & $70 \mathrm{~min}$ & 50 & 1.0 \\
\hline & 3, $200 \mu \mathrm{mol}$ & $22 \mathrm{~min}$ & 50 & $2 \quad(R)$ \\
\hline
\end{tabular}




\begin{tabular}{|c|c|c|c|c|c|}
\hline \multirow{3}{*}{$\begin{array}{l}\text { BsubpNBE } \\
\text { G105A, } \\
80 \mathrm{mg}^{\prime} \\
350 \mathrm{U}^{\mathrm{C})}\end{array}$} & $\mathbf{1}, 200$ & jmol & $60 \mathrm{~min}$ & 54 & $4 \quad(S)$ \\
\hline & 2,200 & $\mu \mathrm{mol}$ & $150 \mathrm{~min}$ & 50 & $1.3(S)$ \\
\hline & 3,200 & $\mu \mathrm{mol}$ & $22 \mathrm{~min}$ & 50 & $19(R)$ \\
\hline
\end{tabular}

Reactions were carried out at pH 7.5 and $40{ }^{\circ} \mathrm{C}$ (AChEs: at $\left.25^{\circ} \mathrm{C}\right)$. Enantiomeric excesses and conversions were determined by GC on a chiral column. Enantioselectivity was calculated according to chen et al. [33]. Shown enantioselectivities are averages of values calculated at different time points in at least two individual experiments. Conversions are examples of one single experiment. The error margin of the determined enantioselectivities lies within $\pm 10 \%$

a) according to manufacturer, b) Ellman assay towards acetylthiocholine, c) towards $p-N P A, d)$ configuration of the preferred enantiomer is indicated in parentheses. 